\title{
FENOMENOLOGIA CLÍNICA DAS PERTURBAÇOES DA PERSONALIDADE
}

\author{
Victor Amorim Rodrigues \\ Instituto Superior de Psicologia Aplicada
}

É propósito desta comunicação propor uma leitura compreensiva, de tipo fenomenológico, das perturbações da personalidade, em contexto clínico. Atingir esta meta exige um esclarecimento introdutório dos sentidos do método fenomenológico e do âmbito clínico assim como uma interpretação da existência perturbada, não relativamente a aspectos ônticos ou seja manifestações específicas psicopatológicas (como delírios, alucinações, obsessões, compulsões, evitamentos fóbicos, etc.) mas no que diz respeito aos aspectos visíveis do próprio estar-no-mundo-com-os-outros entendido como personalidade. O desenrolar histórico da aplicação do método fenomenológico à psicopatologia, iniciada por Jaspers na obra Psicopatologia Geral, de 1913, não tem aqui relevância.

O título da comunicação sugere que iremos partir de uma categoria diagnóstica, do âmbito da psicopatologia, e apresentar uma leitura ou interpretação fenomenológica de uma ou do conjunto destas perturbações, como mais uma leitura a juntar a outras já existentes de natureza biológica, dinâmica, cognitiva ou inter-pessoal. Existem de facto boas razoes para reflectir sobre o que seria uma compreensão fenomenológico-existencial das perturbações da personalidade sobretudo pelo lugar especial que estes distúrbios ocupam nas classificações das, assim chamadas, doenças mentais e no conjunto do edifício psicopatológico. Não é esta a meta desta intervenção mas antes reflectir sobre a fundamentação desta e doutras leituras já existentes no próprio ser-do-homem ou seja no especificamente humano. Sobre a necessidade e relevância desta fundamentação falaremos mais adiante. 


\section{Fenomenologia em contexto clínico}

Por fenomenologia entendemos aqui um sentido de método. Não se trata portanto da aplicação de uma qualquer Weltanschauung filosófica à clínica psicológica ou psiquiátrica mas de um método que permita o esclarecimento do sentido do sofrimento psíquico no horizonte da essência do homem ou seja da sua existência.

O rigor do método só admite que se tenha em conta os fenómenos, etimologicamente o que brilha, surge ou se mostra pelo que, devido a este pensamento rigoroso, não são utilizados edifícios conceptuais erigidos em terreno movediço, afirmações arbitrárias e noções não rigorosamente esclarecidas. Também todos os frutos da especulação conceptual, inferidos por um esforço explicativo (integração super-egóica, mecanismos de defesa, relações de objecto internalizadas ou, noutro contexto, esquemas cognitivos nucleares e periféricos) não podem ser utilizados sem um esforço clarificador das suas condições de possibilidade e exposição dos pressupostos da sua utilização.

Fenomenologia, o tema de todo este nosso encontro, na sua essência fica expressa na célebre injunção de Husserl de "regresso às próprias coisas" dito de outra maneira deixar que o que se mostra se mostre a si mesmo, sem intermediações prévias teóricas ou de outro tipo. E se o que se mostra é o modo de ser dos entes então fenomenologia, para o que aqui nos interessa é ontologia.

E como estamos no campo da clínica humana o que nos interessa é o modo de ser desse ente que põe a questão do sentido do seu ser, ou seja o ser humano. Estamos portanto da região de fenómenos que dizem respeito especificamente ao ser humano. Parece evidente mas não é liquido que seja o caso.

Ao pensarmos nas principais correntes da psicoterapia, psicologia clínica e psiquiatria, aparentemente ciências humanas, nada mais lógico do que esperar que se fundamentem no ser desse ente a que chamamos ser humano. Está longe porém de ser o caso. Daí defendermos a urgência, de um pensamento que reoriente a clínica psicopatológica para uma reflexão sobre os seus fundamentos, não apenas por motivos académicos mas porque está em jogo a própria re-humanização da clínica. É aqui que a fenomenologia pode dar uma contribuição essencial, recentrando a clínica humana no ser deste ente tão diferente dos outros entes que através da sua abertura ao mundo permite que esses outros entes se mostrem.

A fenomenologia é um método mas também a clínica é um método. Método descoberto empiricamente no seio da medicina, que sobreviveu através dos séculos, transmitido de mestre a discípulo e tão atractivo que foi adoptado por outras disciplinas não-médicas da psicologia à pedagogia, da sociologia à criminologia. O que haverá de tão atractivo neste método que, sem rigorosos estudos experimentais de sustentação, não só sobrevive há milénios mas está na base das legis artis de várias profissões de ajuda? Clínica deriva da palavra grega Kline que significa leito, cama. É portanto na cabeceira da cama do doente que nasce a clínica. Não do doente em geral mas daquele 
doente em concreto, único, singular, daquele que está deitado, em sofrimento. A lógica da clínica é a lógica do específico, do singular, do único. Já a lógica da ciência é a lógica do universal. A clínica é a passagem do universal ao caso concreto por isso assenta ainda hoje no estudo de caso. Fenomenologia clínica será portanto o estudo do modo de ser deste ente concreto que, na cama ou no cadeirão do consultório, põe a questão do seu ser. Não uma reflexão sobre o ser em geral mas um empenhado e geralmente angustiado questionamento sobre si-mesmo. Uma análise existencial é portanto um exercício clínico concreto que pode centrar-se sobre um modo de ser sentido como restritivo, inflexível, mono temático, limitador da liberdade, numa palavra, perturbado. Se esta perturbação é sentida, não como um estado temporário que sobrevém ao sujeito mas como algo intrínseco ao seu modo de estar no mundo então estamos em presença de uma assim chamada perturbação da personalidade.

Reparemos que só quem tem formação clínica está em condições de facilitar este questionamento pessoal no âmbito psicoterapêutico. O filósofo mantém-se sempre num âmbito geral de uma analítica.

Ellenberger (1958), um importante autor da história da psicologia e psicoterapia avança com um exemplo, talvez um pouco extremado, mas útil na compreensão dos âmbitos respectivos da fenomenologia filosófica e da fenomenologia clínica (a que chama psiquiátrica). Compara a relação destas à relação entre a física de partículas e a especialidade médica da radiologia. Claro que o físico saberá muito mais sobre a natureza da radiação do que o radiologista mas a sua aplicação ao diagnóstico de doenças compete exclusivamente a este último e seria insensato o físico que quisesse discutir a interpretação de uma radiografia ou de uma TAC com qualquer médico e ainda mais com um radiologista.

Fenomenologia clínica não deve pois ser confundida com qualquer actividade de aconselhamento filosófico, que parte de outras premissas.

\section{Relevância actual das perturbações da personalidade}

Já atrás nos referimos ao lugar particular das perturbações da personalidade no âmbito da psicopatologia. Desde logo pela sua importante prevalência e impacto, na população geral (calculada em cerca de 10\%), e muito sensivelmente nos consultórios dos psiquiatras, psicólogos clínicos e psicoterapeutas de um modo geral. É hoje voz corrente, entre os clínicos da mente, o queixume de que os "bons e velhos neuróticos" dos tempos pioneiros de Freud se estão a tornar numa espécie em vias de extinção, a chamada grande histeria que deixava a boca aberta dos espectadores embasbacados das aulas de Charcot, entre os quais esteve Freud, com o seu misto de paralisias, anestesias e contorções convulsiformes, de sabor levemente erótico, essa então estaria quase tão extinta como o pássaro dodó. 
Em vez desses "espécimes" teríamos agora multidões de personalidades narcísicas, psicopáticas e sobretudo esse diagnóstico tão popular quanto usado sem rigor que é o de patologia borderline.

$\mathrm{O}$ impacto destas perturbações ultrapassa o estrito âmbito clínico sendo muito importantes as consequências sociais em termos de sofrimento familiar e conjugal, abstinência e conflitos laborais e implicações legais.

Claro que as principais correntes psicoterapeuticas responderam ao repto dos tempos e encontramos, desde os anos 80 do século passado, excelentes manuais propondo modificações específicas da técnica de modo a manterem a eficácia, diante destes pacientes considerados como particularmente difíceis (Kernberg, 1984; Beck \& Freeman, 1993; Linehan, 1993; Benjamin, 1996).

Paralelamente os psiquiatras de orientação biológica mostram incómodo diante deste diagnóstico, tendendo a referenciar ou mesmo "despachar" estas pessoas na primeira oportunidade, pondo em causa que ainda estejam em presença de patologia mental ou ainda pior fazendo uso da gíria psiquiátrica brejeira " instável, borderline, pois sim, são mas é psico-malandros, só querem é chatear".

À primeira vista é surpreendente que médicos (e também alguns psicólogos) que supostamente estão em profissões que só existem com a finalidade de prestar auxilio a outros seres humanos, reajam desta forma tão rude. Se, no entanto, num segundo momento, nos apercebermos que estas pessoas desafiam a mítica omnipotência médica e expõem a incapacidade de tudo fazer desaparecer com uma pílula milagrosa percebemos mesmo as reacções mais intempestivas. É que ainda não há pílulas que modifiquem o carácter de um ser humano.

Há fármacos anti-depressivos, anti-psicóticos, anti-insónias (hipnóticos), anti-ansiedade (ansiolíticos) mas não anti-arrogância, anti-egoísmo ou anti-teatralidade.

Deste modo é compreensível que à impotência se siga a zanga e desta à rejeição vai um pequeno passo. E eis os nossos pacientes "borderline" rapidamente encaminhados para a psicoterapia.

Aí chegados encontram psicoterapeutas dinâmicos, cognitivos, comportamentais e inter-pessoais preparadíssimos para os receber, com os manuais estandardizados acima referidos, prevendo o desenrolar da terapia por vezes até sessão a sessão e com as respostas aos principais problemas que possam surgir. Sendo inegavelmente eficazes as várias intervenções psicoterapêuticas desenvolvidas nas últimas décadas, põe-se a questão da necessidade e oportunidade de apresentar uma outra leitura desta patologia que por sua vez (já se adivinha) poderá dar origem a uma forma outra de intervenção terapêutica.

Certo é que os autores do campo existencial em psicoterapia não têm sido pródigos na abordagem da patologia da personalidade ou até sobre o tema psicológico da personalidade tout-court. Só a convicção de que os modelos teóricos dominantes na psicologia do nosso século, falham de alguma maneira o alvo, não porque estejam errados mas porque podem ser integrados e subsu- 
midos, como aspectos ônticos, de uma perspectiva que permite ver mais longe porque paradoxalmente olha para o que está mais perto e se coloca numa posição mais originária. Esta posição sobre o campo psicológico e a necessidade da uma reorientação necessita de ser esclarecida.

\section{Recentramento da clínica humana na Humanitas e seus desvios contemporâneos}

Pensemos na psicologia comportamental em primeiro lugar. Os vários tipos de condicionamento, com aplicações terapêuticas inegáveis, embora em campos muito restritos, foram como todos sabem descobertos em animais. As técnicas de modificação de comportamento a que deram origem funcionam tanto em homens como em ratos, cães, macacos, periquitos ou moluscos. A boutade dos psicólogos humanistas norte-americanos de que esses grandes tratados de psicologia comportamental são na realidade exaustivas monografias sobre o comportamento, em cativeiro dos pombos e dos ratinhos de laboratório tem alguma razão de ser!

Estamos portanto muito afastados do que já tínhamos pensado como o mais lógico e que nesta perspectiva comportamental se revela o mais ilógico isto é que uma clínica humana deveria ter o seu fundamento no modo de ser do homem, na sua Humanitas.

Não que defendamos que o homem não é também um animal mas antes que é no que há de especificamente humano e não na animalitas que se há-de fundamentar a psicoterapia.

Quanto à psicologia cognitiva, paradigma dominante actual da psicologia, que veio substituir o comportamentalismo a partir dos anos 60 , e que se casa tão bem com as neurociências e com a inteligência artificial, também está longe de tomar como fundamento o ser do homem. Novamente o mais lógico é tomado como o mais ilógico. Para a psicologia cognitiva a dupla cérebro/ mente funciona como um processador de informação logo como um computador. Foi com a invenção dos computadores que este campo científico ganhou forma e são os computadores os modelos a partir dos quais são compreendidos os seres humanos ("No representations, no computations. No computations, no mind" diz-nos Fodor, 1980). É assim que na psicoterapia cognitiva se fala em inputs, outputs, viéses no processamento da informação, erros cognitivos, esquemas cognitivos etc. Defende-se mesmo que a relação mente-cérebro é semelhante á relação que existe entre o software e o hardware do computador. Mais uma vez não pretendemos negar a existência de processamento de informação no homem mas sim que seja por aí que passa a sua Humanitas.

A essência do computador é computar. Computar é processar informação. O computador é uma máuina que processa informação de resto em alguns campos muito melhor que um ser humano. A Humanitas do homem escapa a qualquer maquinismo e os nossos pacientes sabem-no bem indig- 
nando-se quando os queremos circunscrever a mecanismos e maquinismos de qualquer espécie.

A psicoterapia cognitiva passa ao lado do ser do homem porque não tem em conta esta diferença intransponível entre o ente homem e qualquer ente máquina ainda que seja uma máquina sofisticada que até joga xadrez e resolve problemas matemáticos. O computador não sabe que é um computador! Não põe portanto a questão do seu ser e por isso nunca poderia fazer terapia, que parte sempre da possibilidade exclusivamente humana, bem expressa por Santo Agostinho, de em qualquer momento poder "tornar-se para si próprio uma questão". Aqui começa o humano!

Um programa de computador de nível elevado derrota facilmente qualquer jogador de xadrez de nível médio o que pode ser muito irritante, mas no final paradoxalmente a maquina não ganhou porque este "ganhar" só pode aparecer à abertura que permite que a vitória ou derrota surjam enquanto tais. O computador ganhou mas só o homem sabe disso, a máquina não sabe que ganhou e mais ainda, ganhou mas nem sabe que está a jogar xadrez.

Sem querermos ir tão longe compreendemos o severo juízo da psicanalista francesa Roudinesco (2005) quando afirma que "a psicologia cognitiva (ou cognitivismo) é uma mitologia cerebral que repousa na ideia de uma possível adequação entre o cérebro e o pensamento, por sua vez fundada na analogia entre o funcionamento cerebral e o computador. Derivadas de estas teorias, as terapias cognitivo-comportamentais consistem numa mescla de adestramento dos corpos, de técnicas de persuasão e de condicionamento das consciências".

E quanto à psicanálise? Não queremos ser injustos com as mais recentes correntes da psicanálise relacional, algumas assumidamente inspiradas na fenomenologia e na hermenêutica (Orange, Atwood \& Stolorow, 1997; Shafer, 1997) mas está já bem estudada a influência dos modelos da física oitocentista na metapsicologia freudiana e só a consideração dos conceitos ainda hoje utilizados na compreensão da mente humana tais como força, vectores, depósitos ou quanta de energia, mecanismos de defesa, etc. chegariam para nos convencer. E que dizer do projecto da neuropsicanálise que a todo o custo procura legitimar o estatuto científico da psicanálise através de uma aproximação com as neurociências cognitivas, propondo mesmo uma neurobiologia do inconsciente (Stora, 2006)?

Não se leia aqui de modo "lógico" uma tentativa de caricaturizaçao dos paradigmas psicodinâmico e cognitivo-comportamental, não só porque nos referimos aos fundamentos destes paradigmas na sua origem (e não aos seus desenvolvimentos actuais) mas também porque defendemos que os conhecimentos ali obtidos estão certos se restritos ao âmbitos das respectivas investigações. 


\section{Compreensão ontológica das perturbações da personalidade}

Como atrás referido o estudo de caso permanece uma metodologia fundamental no âmbito clínico pelo que, através de uma vinheta clínica, procuraremos explicitar a nossa posição.

\section{O caso de João Leandro}

João Leandro é um médico neurologista, de 45 anos que trabalha num hospital central de Lisboa. Todo o seu percurso profissional esteve marcado por conflitos sucessivos com os colegas médicos mas também com outros profîssionais de saúde e com alguns pacientes. João demorou cerca de 10 anos a concluir o período de especialização (internato) em neurologia que está programado para ser realizado em 5 anos. Com expedientes sucessivos (entre os quais repetir o difícil exame de entrada nos internatos médicos para assegurar o direito legal a repetir este período) foi evitando o exame de saída, por estar convencido que tudo estava decidido à partida, com os examinadores combinados para o "chumbar". Tinha também a convicção (que mantém) que os seus superiores o vigiam, para aproveitar o mínimo pretexto para o despedir pelo que se mantém hipervigilante no serviço, sempre atento aos gestos e conversas que possam significar a sua "desgraça". A conflituosidade começou logo no primeiro ano do internato, quando pediu para mudar de orientador de formação alegando que este não lhe ensinava nada, com o propósito de que fizesse má figura. Apesar de o director de serviço ter anuído com a mudança de orientador, também este foi acusado pouco depois de o querer prejudicar ao distribuir-lhe os doentes mais difíceis. Acabou por mudar de serviço para alívio dos profissionais mas no novo serviço discutiu e incompatibilizou-se com os enfermeiros afirmando que estes mudavam as suas medicações e aumentavam secretamente as doses para que os seus doentes piorassem. Terminado o internato conseguiu um lugar no hospital, dado que tecnicamente todos reconheciam os seus conhecimentos, mas está sempre isolado, falando o mínimo indispensável com os colegas, com atitude de desconfiança marcada. Sempre que entra um novo interno avisa-o de que "aqui todos querem lixar o parceiro, tem cuidado".

A nível privado João mora sozinho, não tem amigos nem acredita nessa possibilidade "não há amigos, as relações humanas são só um jogo de interesses". Não tem nenhum relacionamento amoroso fixo preferindo manter uma sucessão rápida de "namoros" de curta duração sem abertura a compromissos ("as mulheres são todas umas cabras, querem é lixar a vida a um homem, o melhor é ir para a cama e não aquecerem o lugar antes que nos estraguem a vida"). Destas ligações rápidas nasceram duas filhas (de mães diferentes) estando a correr um processo legal de calúnia injuriosa contra o João movido pelo avô materno da filha mais velha, dado que foi acusado de pedofilia: "eu bem vi, mesmo à frente 
de toda a gente na sala, sentava a miúda de 5 anos no colo e punha-lhe a mão sobre a coxa fingindo que a estava a segurar, claro que lhe chamei a atenção".

João nasceu e cresceu no interior africano, no período colonial, pelo que embora criança viveu com muita mágoa os tempos da descolonização. Ainda hoje são chocantes as lembranças de como os companheiros de brincadeira de repente viraram inimigos e João passou a persona non grata pelo facto de ser o único menino branco da aldeia.

Após o regresso a Portugal os pais decidem ir "tentar a vida" no Brasil e durante os preparativos da viajem João adere com o entusiasmo dos seus dez anos, imaginando como seria a sua vida num país tropical como a "sua terra". Para sua surpresa os pais partem definitivamente, levando o irmão dois anos mais novo e deixam João num colégio interno. João nunca soube o motivo deste abandono...

Por exigência do actual director de serviço, sob ameaça de processo disciplinar devido a queixas de alguns pacientes, João foi "conversar" com uma psicóloga que presta serviço no hospital sem contactos directos com o serviço.

João contrariado deixa claro que não atribui credibilidade a alguém "sem formação médica" declarando: "a psicologia é só conversa de chacha, aposto que não sabe os nomes e localização dos núcleos basais". Dada esta postura e consequente impossibilidade de trabalhar com o João a psicóloga propõe-lhe referenciá-lo a um psiquiatra de outro hospital dizendo que assim poderia falar com um colega. João responde jocoso "psiquiatras nem pensar, são todos malucos! A psiquiatria vai desaparecer e ser substituída pela neurologia do comportamento, não é carne nem peixe. Quando encontro um psiquiatra meto-o logo no lugar perguntando-lhe qual é o órgão que ele trata. Deve saber que um médico a sério ou tem um órgão ou uma técnica. Como o cérebro é da neurologia, a psiquiatria não tem uma coisa nem outra. Farto-me de rir!".

\section{Discussão do caso}

De acordo com os critérios actuais o caso de João Leandro poderia ser diagnosticado como um caso de perturbação da personalidade de tipo paranóide. Não é difícil identificar um padrão geral de desconfiança, estável no tempo e manifesta numa vasta gama de situações. Está patente uma atitude de suspeita permanente que ocasiona conflitos inter-pessoais e rejeições que formam um padrão de repetição que por sua vez reforçam e confirmam a desconfiança. Querelância, hipersensibilidade à crítica e tendência a formular acusações sem fundamento objectivo são outras características da personalidade do João Leandro.

Já expusemos noutro lugar (Amorim Rodrigues \& Gonçalves, 2004) as diferentes formulações teóricas concernentes à origem das personalidades perturbadas pelo que aqui vamos questionar o que seria uma proposta de compreensão existencial e o que esta teria de diferente face a estas propostas psicológicas ou biológicas anteriores. 
Fenomenologicamente, o cérebro vem sempre depois, pelo que o verdadeiro contraste dialogante dá-se com as perspectivas psicanalíticas e cognitivas. O que está em causa é, desde logo, a visão sobre a natureza da psique. Este é o ponto original, cuja discussão é sistematicamente adiada e evitada nos livros de texto psicológicos. A pergunta sobre a essência do psíquico, a interrogação do que seja isso que chamamos mente ou psique seria "logicamente" a questão tratada em primeiro lugar num tratado de psicologia, ou psiquiatria ou psicoterapia, uma vez que o prefixo psi, que todas estas áreas ou actividades científicas ostentam, as fazem apresentar como ciências da psique. Curiosamente quando os textos universitários de introdução à psicologia definem psicologia como o estudo científico do comportamento e funcionamento mental nunca explicitam o que seja essa mente que "funciona", como se a natureza da mente fosse dessas ideias que, aparecendo de modo tão claro e distinto ao leitor, dispensassem qualquer esclarecimento posterior. A pergunta é evitada mas dela depende não só toda a visão que teremos do próprio campo psicológico mas também do lugar do psíquico no relacionamento com as outras dimensões do humano seja o bios ou o socius. Por isso Nietzsche na Vontade de Poder pôde astutamente afirmar que sendo o corpo uma ideia mais surpreendente, mais rica mais clara e compreensível do que a velha alma deveria ser colocada metodicamente em primeiro lugar.

Uma crítica fenomenológica às concepções psicodinâmicas e cognitivas da psique aponta para que, nestas, está pressuposta (ainda que nem sempre reflectidamente) a mente como uma "caixa" contendo representações que, por sua vez, se refiram a coisas que estão num mundo externo a essa "caixa". Neste contentor as representações não estão paradas, sofrem diversos tipos de tratamento e transformações, todavia uma concepção deste tipo tem sempre o problema de resolver de que maneira as representações podem "representar" algo exterior. Neste tipo de visão da psique é primordial a distinção entre mundo externo e realidade interior (nao os separar é psicose) e a afirmação de uma realidade psíquica irredutível à realidade biológica ou social.

O problema da "ligação" interno/externo não aparece se pensarmos a psique não como um recipiente mas como um "aberto" para o mundo, lugar onde surgem os entes enquanto entes. Esta abertura de sentido é no entanto estruturada e as determinações existenciais da estrutura constituem o ser do homem. Sempre que aspectos ônticos concretos e experiências específicas são confundidos (devido à sua intensidade e ao significado que lhes são atribuídas) com os próprios constituintes estruturais todas as experiências posteriores passarão a ser interpretadas a partir daquelas.

No caso do João Leandro as experiências de traição e abandono, cujo impacto emocional é difícil sequer imaginar, passam a fazer parte da sua mundividência, pelo que o ser-com-os-outros, que é uma determinação da existência, fecha-se à possibilidade da confiança, lealdade ou ajuda desinteressada nas relações inter-pessoais. 
A personalidade, normal ou perturbada, traduz um modo unidimensional de estar no mundo e compreendê-la é mostrar de que maneira o ser humano foi solicitado.

Compreender os distúrbios da personalidade a partir das determinações constituintes do ser-no-mundo é avançar no caminho de um entendimento ontológico logo mais originário do que as descobertas psicodinâmicas ou cognitivas que surgem agora como diferentes caminhos parciais, certos no âmbito das metodologias de investigação que por sua vez condicionam os resultados (se procuro ligar o aqui e agora com outro tempo e outro lugar como se faz numa interpretação genética, consigo-o, assim como se procuro erros lógicos - no processamento das dados, encontro-os) não sendo, no entanto legítimo definir o ser do homem a partir da metodologia adoptada à partida.

Toda a patologia é perda de liberdade, restrição do vir-a-ser. No caso da patologia da personalidade o que está em jogo é uma pré-compreensão restritiva (fechada) e não tematizada do ser-com que termina numa situação existencial de solidão (eis-me só e incompreendido num mundo que me rejeita) e ocultação dos aspectos "positivos" do Mitsein: solidariedade, confiança, cooperação, camaradagem e amor.

\section{Referencias bibliográficas}

Agostinho (1958). Confissões. Porto: Livraria Apostolado da Imprensa.

Amorim Rodrigues, V. \& Gonçalves, L. (2004). Patologia da Personalidade-Teoria, Clínica e Terapêutica, Lisboa: Fundação Calouste Gulbenkian.

Beck, A. \& Freeman, A. (1993). Cognitive Therapy of Personality Disorders. New York: The Guilford Press.

Benjamin, L. (1996). Interpersonal Diagnosis and Treatment of Personality Disorders. New York: The Guilford Press.

Fodor, J. (1980). The Language of Thought. Harvard University Press.

Linehan, M. (1993). Cognitive-behavioral Therapy for Borderline Personality Disorder. New York: Guilford Press.

Jaspers, K. (1948) General Psychopathology. London: Oxford Press.

Kernberg, O. (1984). Severe Personality Disorders: Psychotherapeutic Strategies. New Haven: Yale University Press.

May, R., Angel, E. \& Ellenberger, H. (1958). Existence - A New Dimension in Psychiatry and Psychology. New York: Basic Books

Orange, D., Atwood, G. \& Stolorow, R. (1997) Working Intersubjectively: Contextualism in Psychoanalytic Pratice. Hillsdale: The Analytic Press.

Roudinesco, E. (2005). Philosophes dans la tourmente. Paris: Librairie Arthème Fayard.

Schafer, R. (1997). Tradition and Change in Psychoanalysis. London: Karnac Books. Stora, J-B. (2006). La Neuro-Psychanalyse. Paris. PUF. 


\begin{abstract}
Personality disorders are among the most intriguing and fascinating mental disorders. As they are characterized by pathological traits, not signs and symptoms, they are unsuitable for treatment with psychotropic drugs or other biological treatments.

A psychological understanding of these disorders is possible based on cognitive or psycho-dynamic explanations but the author argues that these theoretical models miss the essential point, as they lack a foundational ground on what is specifically human in human beings, their humanitas. Any deviation from this ground might lead to the so called de-humanization of medicine or other clinical disciplines.

This paper proposes an existential understanding of personality disorders grounded on the being of man. A clinical practice oriented towards the phenomenological method conceives human beings as an "opening of meaning" where the entities of the world can show themselves. The "opening" however is structured and if one revealed content (for instance a biographical event) is misunderstood as a structural component that might generate a set of interrelated pathological personality traits.

A clinical case is presented to illustrate this process.
\end{abstract}


